\title{
Study on Acoustic Emission Characteristics and Mechanical Behavior of Water-Saturated Coal
}

\author{
Muhammad Ali $\mathbb{D}^{1,2,3,4,5}$ Enyuan Wang $\mathbb{D}^{1,2,3}$ Zhonghui Li, ${ }^{1,2,3}$ Haishan Jia, ${ }^{1,2,3}$ \\ Dexing Li, ${ }^{1,2,3}$ Izhar Mithal Jiskani $\mathbb{D}^{2,6}$ and Barkat Ullah ${ }^{3}$ \\ ${ }^{1}$ Key Laboratory of Gas and Fire Control for Coal Mines (China University of Mining and Technology), Ministry of Education, \\ Xuzhou 221116, China \\ ${ }^{2}$ State Key Laboratory of Coal Resources and Safe Mining, China University of Mining and Technology, Xuzhou, \\ Jiangsu 221116, China \\ ${ }^{3}$ School of Safety Engineering, China University of Mining and Technology, Xuzhou, Jiangsu 221116, China \\ ${ }^{4}$ Sustainable Advanced Geomechanical Engineering Department, MCE, National University of Sciences and Technology, \\ Islamabad, Pakistan \\ ${ }^{5}$ Department of Mining Engineering, Balochistan University of Information Technology, Engineering and Management Sciences, \\ Quetta, Pakistan \\ ${ }^{6}$ School of Mines, China University of Mining and Technology, Xuzhou, Jiangsu 221116, China
}

Correspondence should be addressed to Muhammad Ali; muhammad.ali@cumt.edu.cn and Enyuan Wang; weytop@cumt.edu.cn Received 15 April 2021; Accepted 21 July 2021; Published 14 August 2021

Academic Editor: Feng Xiong

Copyright $\odot 2021$ Muhammad Ali et al. This is an open access article distributed under the Creative Commons Attribution License, which permits unrestricted use, distribution, and reproduction in any medium, provided the original work is properly cited.

In terms of coal's stability and failure, soaking time and water content play a significant role in geotechnical engineering practice. To determine the soaking time effect on the mechanical behavior of coal samples and the response of AE (acoustic emission) signal throughout loading, the samples with different soaking times (0-120 hours $(\mathrm{h})$ ) were prepared and tested under uniaxial compression. AE signals were continuously monitored during loading to examine the AE characteristic response via the AEwin Express-8.0 system. The results revealed that the mechanical characteristics of the coal samples decreased with an increase in soaking time. When coal samples were subjected to uniaxial compression, AE events occurred due to the formation of the cracks, which further propagated to cause coal fracture. AE counts and the accumulative counts fluctuated with time and corresponded very well to the load. Therefore, AE counts and the trend of the accumulative counts of AE qualitatively explained the rupture of the coal under stress. In addition, the variation in trends of $\mathrm{AE}$ counts, $\mathrm{AE}$ accumulative counts, and load with time at various phases of all samples were obtained. It is concluded that AE counts increase suddenly during a slow increase phase and peak at the active increase phase. During the attenuation phase, the AE counts first decrease significantly with stress drop, but also a slight increase was observed due to the initiation of secondary cracks. These research results are of great significance as a precursor in coal and rock failure.

\section{Introduction}

The influence of water on rock mass stability is significant due to geological disasters and hazards such as karst collapse $[1]$, water inrush $[2,3]$, landslides, and dam instability $[4,5]$. The literature widely reported that the strength of rock reduces as the water content increases, resulting in an increase in plasticity [6-8]. Water intrusion of rocks containing clay minerals significantly deteriorates the rock [9].
Moreover, the mechanical properties of rocks are also affected by water content that results in a decrease in their uniaxial compressive strength (UCS), elastic modulus, and tensile strength [10]. It is observed that, prior to fracturing, the stress-strain curve of the water bearing rock violently fluctuates in the damaged area [11]. In cold regions, condensation of water in rock pores into ice exacerbates the decrease in rock strength [12]. Water in the rock cracks is one of the most critical factors that lead to the further expansion of the fracture 
network, which ultimately has adverse effects on the rock stability [13]. After triaxial compression tests of water-saturated sandstones, Baud et al. [14] used a micromechanical model to demonstrate the connection between water content and failure modes. It is found that in the presence of water, EMR signals generated by the piezoelectric effect and charge separation are weakened due to the decrease of rock mechanical strength, which eventually leads to the development of fracture characteristics [15]. This is also supported by the literature, as Haberfield and Johnston [16] analyzed the effect of water on fracture toughness of rock, confirming that fracture toughness decreases as a result of water. The results of the notched semicircular bending tests discovered that with increasing water content, the fracture characteristics of rock were weakened [17]. Since understanding the rock behavior is critical to ensuring the long-term stability of underground excavations [18], the deteriorating impact of water content in rock mass needs full consideration while studying rock mass stability.

Coal or rock material releases strain energy in the form of the elastic wave in the process of damage and failure. The phenomenon of this irreversible change is called acoustic emission (AE) $[19,20]$. The $\mathrm{AE}$ monitoring technique is widely used to capture the failure process of rocks by sensing elastic waves. Due to the association of AE to the rock failure process, AE technology has found wide application in coal and rock mechanics research [21, 22]. For instance, Kong et al. [23] studied the AE characteristics for rock failure under compression and identified the four phases of $\mathrm{AE}$ evolution. Filimonov et al. [24] found that an increased loading rate significantly enhanced the AE of salt rock. Shkuratnik et al. [25] investigated the memory effects of AE by conducting uniaxial and triaxial cyclic unloading tests. With recent advancements in electronic technologies and high-speed photography, several modern techniques for rock mechanics research have been commonly adopted in the recent years [26], for example, electromagnetic radiation technology [27, 28], scanning electron microscope, infrared thermal image technology [29], and electrical resistivity technology [22]. However, the application of these technologies is limited to the study of coal and rock damage/failure, while the influence of water content and soaking is rarely considered.

Therefore, the current studies of AE characteristics in the process of rock fracturing rarely involve a water bearing rock, so it is necessary to carry out relevant research. For this study, coal samples were prepared with different soaking times and water contents to conduct the uniaxial compression test and monitor the AE signals. In addition, the AE characteristics of coal samples with different water contents during fracturing were studied. In conclusion, the mechanism of AE generation and the effect of soaking time and water are discussed in detail. These research results are of great significance for water bearing rock stability and as a precursor in coal and rock failure.

\section{Materials and Methods}

2.1. Materials and Sample Preparation. The samples for the test were collected from the coal block taken from the working face. According to the International Society of Rock Mechanics (ISRM), by using a vertical drill machine, $\Phi 50 \mathrm{~mm}$ coal core logs were taken from these coal blocks that were cut in $100 \mathrm{~mm}$ of length as shown in Figure 1. After the coal samples were polished, the diameter and length were measured with a Vernier caliper and weighed by electronic balance.

The coal was then placed in a container, and the initial height of the water was set to $1 / 4$ of the height of the coal sample. After every two hours, the height of the water increased by $1 / 4$ of the samples. Therefore, after 6 hours, the samples were fully immersed in the water. Samples were taken out from water at 24 hours, 48 hours, 72 hours, 96 hours, and 120 hours, respectively, for testing. The water-saturated samples were weighted and placed in sample covered containers to prevent the samples from dryness or get moist. The properties of the processed samples are shown in Table 1. The effect of soaking time on compressive strength and percentage of water absorbed is shown in Figure 2.

\subsection{Experimental System}

2.2.1. Loading System. The experimentation equipment comprised of the axial loading subsystem and $\mathrm{AE}$ data acquisition system. The axial loading subsystem consists of a press (a servo-controlled YAW4306 compression testing machine), a DCS controller, and a Power Test V3.3 controlling program as shown in Figure 3. The press has closed-loop controls. It can carry out continuous stress management and stress retention tests. The maximum bearing capacity is $3000 \mathrm{kN}$, the loading rate is between 600 and $60,000 \mathrm{~N} / \mathrm{s}$, and the accuracy is $\pm 1 \%$. Furthermore, the press can operate in two control modes, i.e., force and displacement, enabling it to perform creep tests, uniaxial compression or tension, cyclic loading, and other tests accordingly.

2.2.2. Data Acquisition System and Sensing System. In this study, Physical Acoustic Corporation manufactured AE System (PCI-2) was used for data recording. The system consists of an 18-bit A/D conversion module, eight digital input/output, and two high-speed and real-time data acquisition channels. It has real-time feature extraction, waveform processing, and transmission capabilities with an occurrence response of between $3 \mathrm{kHz}$ and $3 \mathrm{MHz}$ (at $-3 \mathrm{~dB}$ points). The preamplifier amplifies the signals acquired by the electromagnetic antennas and AE sensors before sending them to the conversion module. In the buffer, the digital signals are saved before being sent for further processing and display. The range of $\mathrm{AE}$ sensor response frequency is 50 to $400 \mathrm{kHz}$, which is equipped with a $20 \mathrm{~dB}$ preamplifier. The band filter operates at frequencies ranging from $20 \mathrm{kHz}$ to $1.5 \mathrm{MHz}$, with input and output impedances exceeding $10 \mathrm{M} \Omega$ and $50 \Omega$.

2.2.3. Test Procedure. The AE monitoring system and the uniaxial compression system were connected as shown in Figure 4, and the tests were performed on specimen (B1, B2, B3, B4, and B5) groups at a loading rate of $50 \mathrm{~N} / \mathrm{s}$ until failure. Before the experimental run, the $\mathrm{AE}$ sensors were attached to the specimens. The preamplifier gain and the AE system threshold values are $40 \mathrm{~dB}$ and $45 \mathrm{~dB}$, respectively. First, a $200 \mathrm{~N}$ initial load was used to secure the specimen against the press head. The AE monitoring system and the 


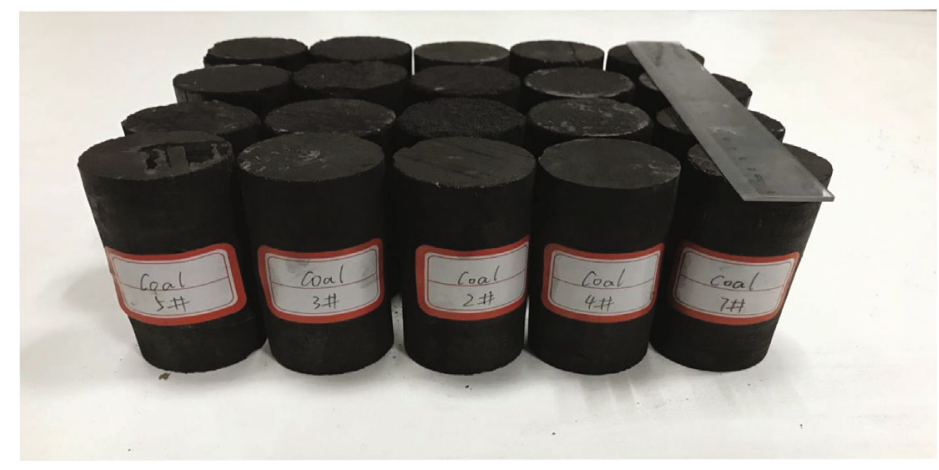

Figure 1: Coal samples with different soaking times.

TABLE 1: Different properties of the coal samples.

\begin{tabular}{|c|c|c|c|c|c|c|c|}
\hline $\begin{array}{l}\text { Sample } \\
\text { no }\end{array}$ & $\begin{array}{l}\text { Soaking time } \\
\text { (days) }\end{array}$ & $\begin{array}{l}\text { Length } \\
(\mathrm{mm})\end{array}$ & $\begin{array}{l}\text { Diameter } \\
(\mathrm{mm})\end{array}$ & $\begin{array}{c}\text { Weight before } \\
\text { saturation } W_{i}(\mathrm{~g})\end{array}$ & $\begin{array}{l}\text { Weight after saturation } \\
\qquad W_{f}(\mathrm{~g})\end{array}$ & $\begin{array}{c}\text { Water } \\
\text { content }(\%)\end{array}$ & $\begin{array}{c}\text { Compressive } \\
\text { strength }(\mathrm{MPa})\end{array}$ \\
\hline B1 & 1 & 100.40 & 49.02 & 226.72 & 234.92 & 3.62 & 10.68 \\
\hline B2 & 2 & 100.04 & 48.02 & 235.78 & 245.92 & 4.30 & 5.89 \\
\hline B3 & 3 & 101.01 & 48.04 & 236.09 & 247.70 & 4.92 & 5.88 \\
\hline B4 & 4 & 100.00 & 48.00 & 238.45 & 254.20 & 6.60 & 5.44 \\
\hline B5 & 5 & 100.00 & 48.80 & 225.61 & 245.13 & 8.65 & 4.38 \\
\hline
\end{tabular}

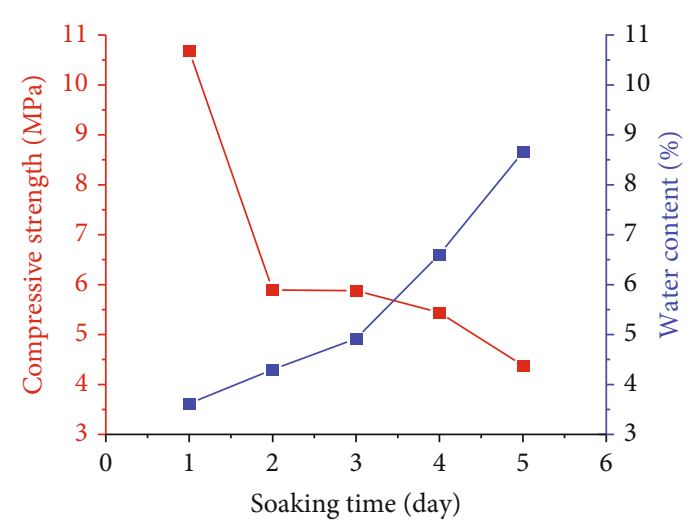

Figure 2: Effect of soaking time on compressive strength and percentage of water content absorbed.

loading system startup at the same time were used to collect $\mathrm{AE}$ data and mechanical parameters.

\section{Results and Discussion}

3.1. Stress-Strain Curves. In this experiment, the stress and strain are achieved from the load and displacement by Equations (1) and (2), individually. Figure 5(a). shows stress-strain curves of coal samples with different water contents and the soaking time.

$$
\begin{gathered}
\sigma=\frac{F}{S}, \\
\varepsilon=\frac{D}{H} .
\end{gathered}
$$

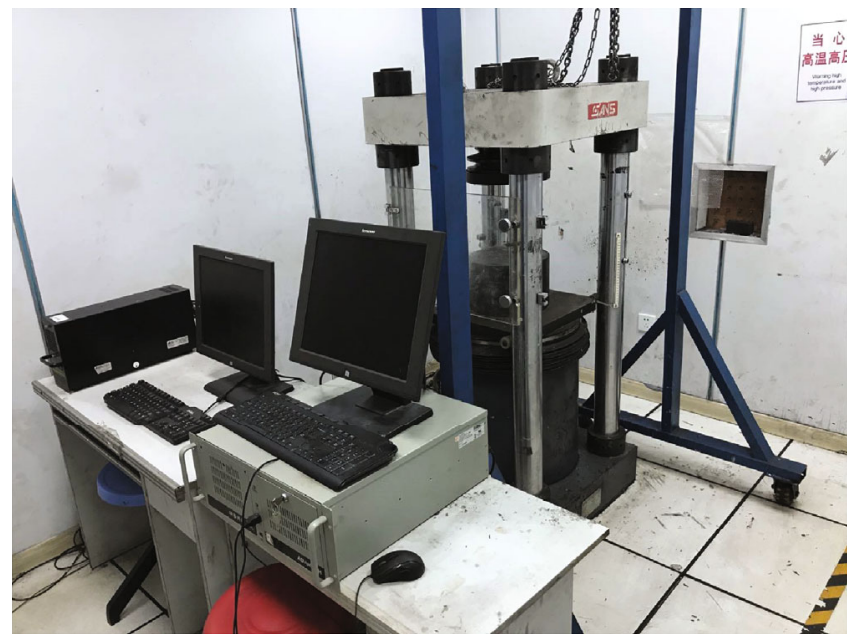

FIgURE 3: Loading experimental system.

In Equation (1), $\sigma$ is the stress, $F$ is the load, and $S$ represents the crossing area of the sample. In Equation (2), D represents the displacement, and $H$ indicates the initial height of the coal sample.

During the loading process, the stress-strain curves of the coal samples gone through different phases, as shown in Figure 5(b), like those mentioned in the literature $[23,30]$. The compaction phase is the phase where the preexisting cracks compressed continuously due to load, and the shape of the stress-strain curve is slightly convex. After the compaction phase, the stress-strain curve became a straight line known as the linear elastic phase, where voids, weak joints, and microcracks were further compressed. However, during this phase, no new cracks were generated, nor did the 
(b)

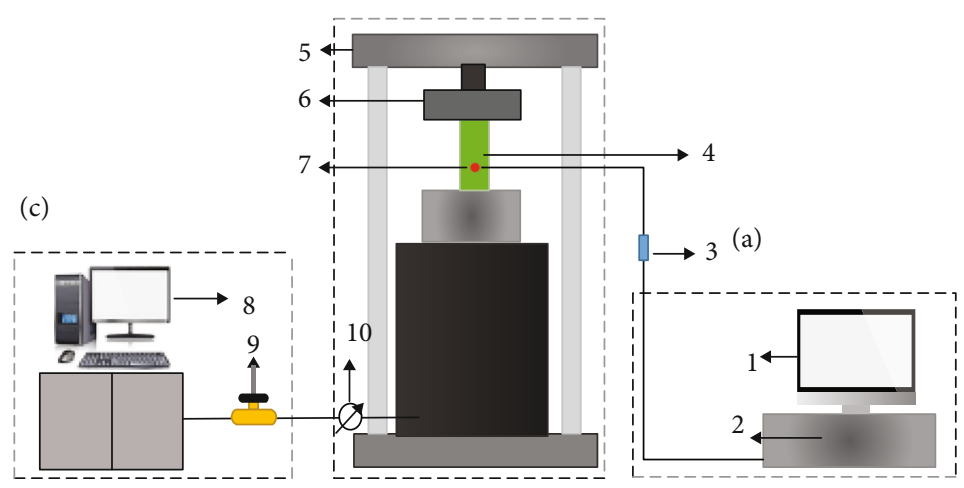

FIGURE 4: Systematic experimental diagram of the acoustic emission system and uniaxial compression system. (a) AE data processing system, (b) Loading control system, and (c) Loading and signal collecting system: (1) computer (for data display), (2) AE monitoring device (3) preamplifier, (4) coal sample, (5) servo hydraulic press, (6) press head, (7) AE sensors ( $\times 4)$, (8) computer (for loading control), (9) valve, and (10) pressure gauge.

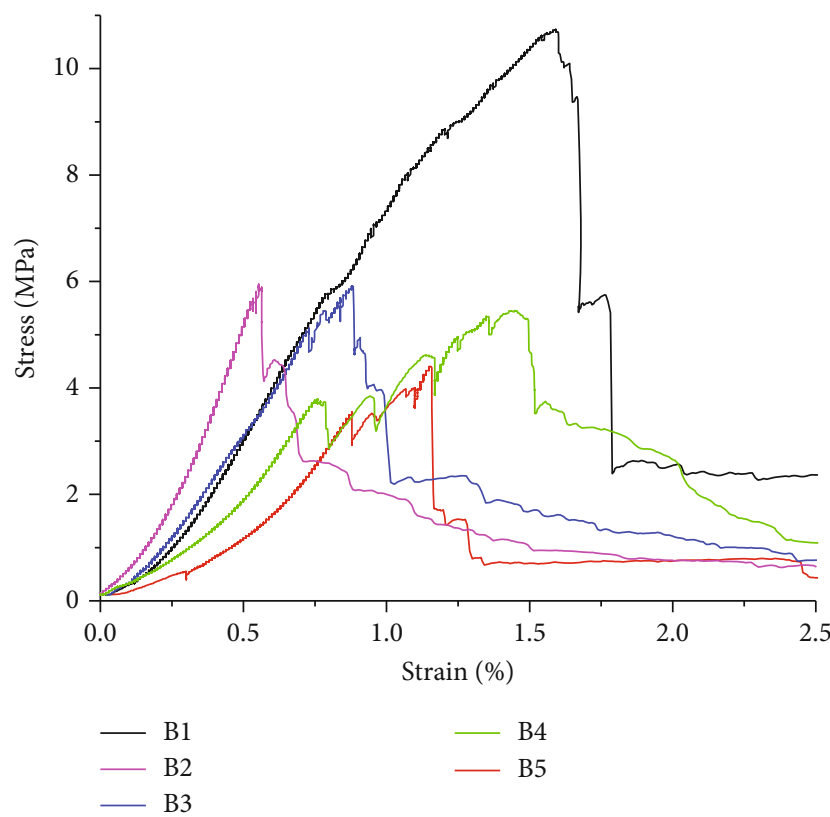

(a)

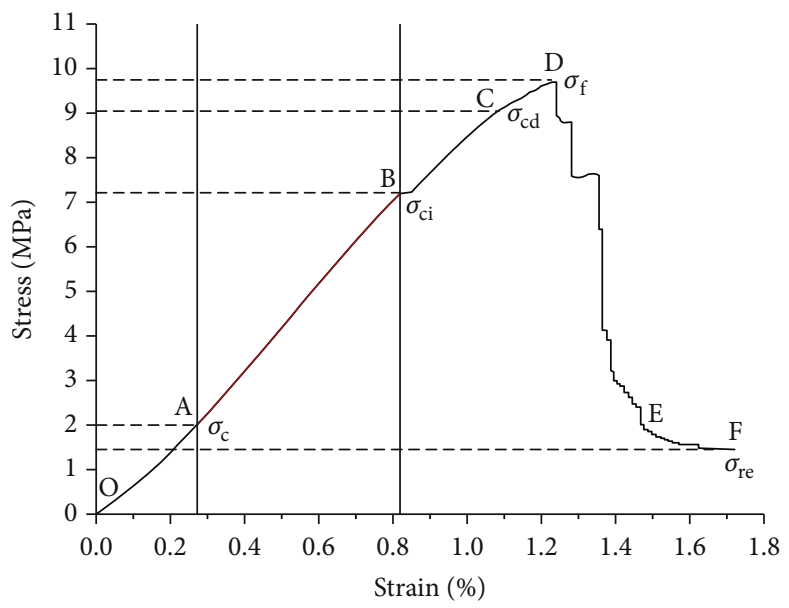

(b)

FIGURE 5: (a) Stress-strain curves of the coal samples. (b) The stress-strain curve through different phases.

preexisting cracks expand due to stress. During the stable crack propagation phase, the level of stress exceeds the stress of crack initiation, resulting in the plastic deformation phase, where the change of the mechanical performance occurs continuously, and the curve of stress-strain deviates from the straight line. In the accelerating crack propagation phase, the microcracks propagate, evolve, and coalesce in the interior to form a fracture network, which leads to energy release and volume expansion. If the stress remains constant, microcracks will begin to form due to the qualitative change. When the bearing capacity of the specimen exceeds the limit, the peak stress is the end of the phase, that is, the peak point on the stress-strain curve. In the postpeak and residual phases, the peak stress falls sharply with the increase of strain until it reaches a constant value. This value of the postpeak stress-strain curve represents the residual stress. While the dislocation slip causes the specimen deformation at this point, they still have a certain bearing capacity.

Many scholars believe that the impact of water and soaking time on the mechanical behavior and propagation of crack of rock mass is basically the result of on the problem of water rock interaction; scholars generally believe that the influence of water on the mechanical properties and crack propagation of rock mass is the result of the combine action of mechanics, physics, and chemistry [30, 31]. For example, the stress level of each specimen varies at each phase, nearly all stress-strain curves (Figure 5) go through the five phases mentioned above. In addition, the peak stress, corresponding to the UCS of the coal samples with different water contents and soaking times, is different. Therefore, it is necessary to 

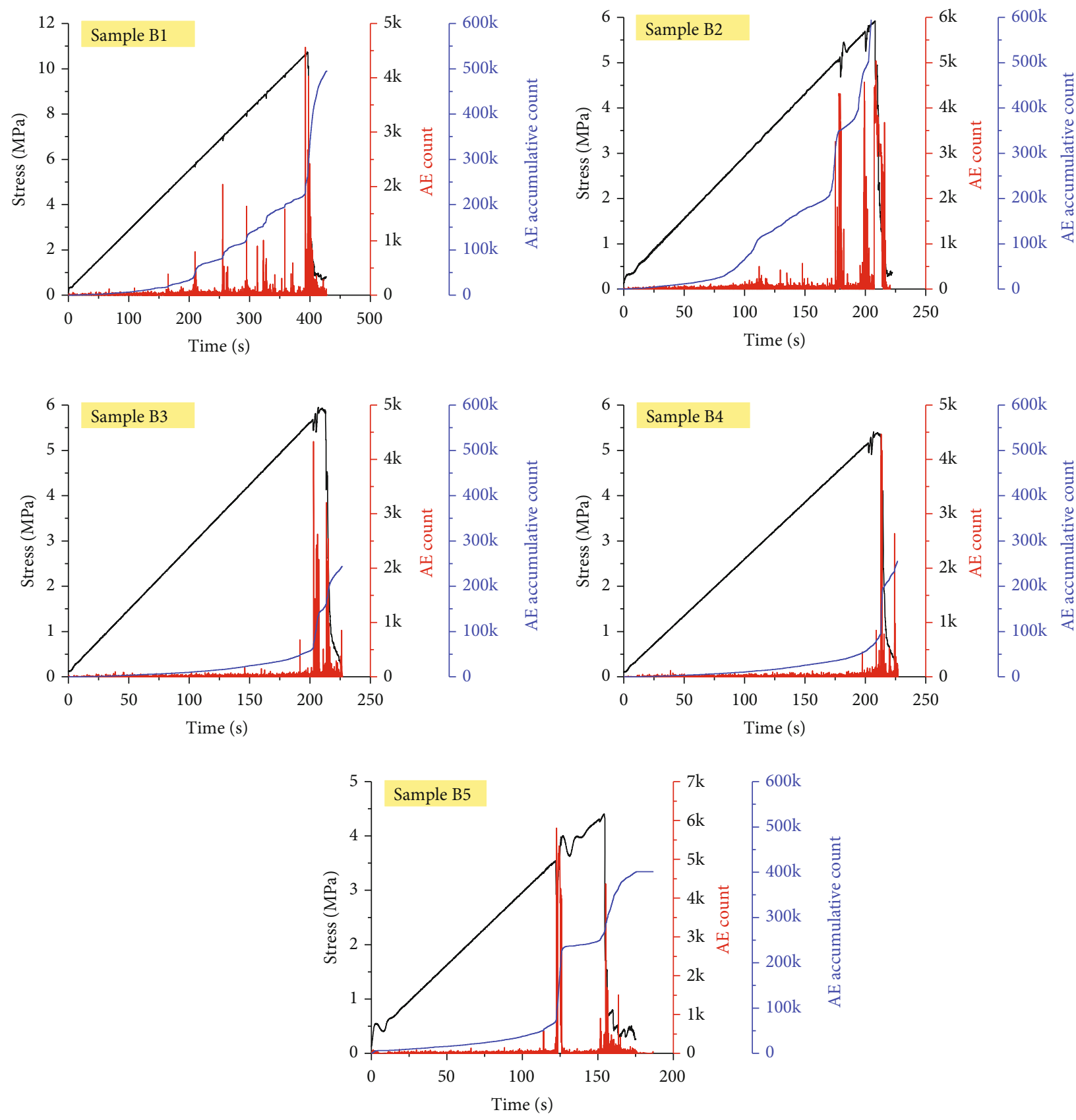

FIGURE 6: The relationship among variation of AE count, accumulated AE count, and stress with respect to time.

analyze the relationship between the water content, soaking time, and the UCS of the coal samples.

Table 1 shows that water-softened samples of rock as it reduced the strength and increase the plasticity of the samples. In addition, with the increase of soaking time, the content of water within coal samples raises, which decreased the UCS. Therefore, B1 has the highest UCS (10.68 MPa) and least water content (3.62\%). In contrast, B5 has the lowest value of UCS (4.38 MPa) and high-water content by percentage $(8.65 \%)$, indicating that with the increase of water content and soaking time; mechanical properties decrease.

It is observed from Figure 6 that the samples with the higher water content and maximum soaking time have smaller modulus of elasticity. From Figure 5(a), it can be seen that coal samples with higher content of water experienced more obvious characteristics. Therefore, coal samples faced higher macroscopic plastic damage, more strain before peak stress, and a greater drop in stress.

3.2. Acoustic Emission during the Loading Process. The variation trend of $\mathrm{AE}$ counts and accumulative $\mathrm{AE}$ counts with time for coal samples with water content at the various soaking times under compression process is shown in Figure 6. During the compression process, AE counts corresponded very well to the stress (load per unit area). To analyze the $\mathrm{AE}$ characteristic in Figure 6, based on the stress-strain curve, 
the process has been distributed in five different phases, shown in Figure 5(b)).

(1) The compaction phase corresponds to the initial activity phase, where a small amount of AE counts resulted because, under stress, the cracks in the samples come close. (2) The linear elastic phase corresponds well to the calming phase because the load is not enough to generate new crakes, and there is a very small value of AE counts. (3) Crack propagation phase corresponds to the slow increase phase, where the initiation stresses generate new cracks resulting in a sudden increase of AE counts and accumulative counts. (4) The accelerating crack propagation phase, corresponding to active increase phase. The new cracks further propagated and developed into macrocracks, which resulted in a large amount of rapid elastic energy. The AE counts and AE accumulative counts are maximum at this phase. (5) Postpeak phase and residual phase corresponded to the attenuation phase; soon after the deformation, there is a significant decrease in stress and $\mathrm{AE}$ counts and $\mathrm{AE}$ accumulative counts. However, due to the existence of residual stress, the coal sample still has a specific bearing capacity, and many secondary cracks begin and further expand, resulting in the AE count rate slightly higher than that before fracture.

To investigate the acoustic emission time series feature in more detail, the $\mathrm{AE}$ counts and $\mathrm{AE}$ accumulative counts parameters were used in the failure process of watersaturated coal, based on the stress-strain curve, the detail process of AE in five different phases of water-saturated samples with different soaking times is shown in Figure 6.

The initial activity phase, where a small amount of AE counts resulted because, under stress, the cracks in the samples come close. However, sample B1 AE counts resulted in much smaller than other saturated samples. In the calming phase where the stress is not enough to generate new crakes, there is a very small value of AE counts in all samples but samples with higher saturation took less stress to reach calming phase. The slow increase phase, where the initiation stresses, generate new cracks resulting in a sudden increase of $\mathrm{AE}$ counts and accumulative counts. In the active increase phase, the new cracks further propagated and developed into macrocracks, which resulted in a large amount of rapid elastic energy. The AE counts and AE accumulative counts are maximum at this phase. B1 took a lot of stress and time to reach this phase, Samples B2, B3, and B4 took almost the same time; sample B5 took the least time. Sample B2 resulted the highest number of $\mathrm{AE}$ counts and $\mathrm{AE}$ counts in this phase. B3 and B4 resulted in approximately the same amount of $\mathrm{AE}$ counts and accumulative counts. In the attenuation phase, there is a significant decrease in stress in all samples and $\mathrm{AE}$ counts and $\mathrm{AE}$ accumulative counts. However, due to the existence of residual stress, the coal sample still has a specific bearing capacity, and many secondary cracks begin and further expand, resulting in the $\mathrm{AE}$ count rate slightly higher than that before fracture. During loading, although the acoustic emission (AE) characteristics of coal samples in different phases with various water contents follow the samples patterns, however, AE characteristics are more obvious in samples with higher soaking time and saturation.

\section{Conclusion}

Laboratory research was conducted to characterize the effect of water content on coal's mechanical properties and the characteristic of acoustic emission under uniaxial loading. The main outcomes are as follows:

(1) The mechanical behavior of coal samples is reduced because of the soaking time of the coal specimens. However, with the increase of soaking time, the influence gradually decreases. Therefore, as the soaking time increases, the UCS decreases

(2) With the increase of soaking time, the water content increases, reducing the mechanical behavior of coal

(3) The loading method passes through five different phases corresponding to the stress-strain curve: the compaction phase, the linear elastic phase, the stable crack growth phase, the accelerated crack growth, and finally the postpeak residual phase

(4) The response of AE signals with different water contents at the different soaking times follows the same pattern; during the entire loading process, however, the peak value of $\mathrm{AE}$ counts was different at the time of failure and is more obvious

(5) When failure occurs, AE counts increase suddenly during a slow increase phase and reached the maximum at the active increase phase. During the attenuation phase, the AE counts first decrease significantly with stress drop, but also a slight increase was observed due to the initiation of secondary cracks. These research results are of great significance as a precursor in coal and rock failure

\section{Data Availability}

The data can be obtained from the corresponding author upon request.

\section{Conflicts of Interest}

The authors declare that there are no conflicts of interest regarding the publication of this paper.

\section{Acknowledgments}

This research was supported by the Key projects of the National Natural Science Foundation of China (51934007 and 52074280), Major scientific and technological innovation projects in Shandong Province (2019JZZY020505), and Development of Jiangsu Higher Education Institutions (PAPD). The authors are also thankful to Sustainable Advanced Geomechanical Engineering Department (SAGE), MCE, National University of Sciences and Technology, Islamabad, for providing facilities. 


\section{References}

[1] H. Bai, D. Ma, and Z. Chen, "Mechanical behavior of groundwater seepage in karst collapse pillars," Engineering Geology, vol. 164, pp. 101-106, 2013.

[2] Z. Huang, X. Li, S. Li, K. Zhao, and R. Zhang, "Investigation of the hydraulic properties of deep fractured rocks around underground excavations using high-pressure injection tests," Engineering Geology, vol. 245, pp. 180-191, 2018.

[3] L. Cao, P. Zhang, J. Zhang et al., "Experimental study of hysteresis characteristics of water-sediment mixture seepage in rock fractures," Geofluids, vol. 2021, Article ID 6692388, 12 pages, 2021.

[4] Y. N. Chan, X. Luo, and W. Sun, "Compressive strength and pore structure of high-performance concrete after exposure to high temperature up to $800^{\circ} \mathrm{C}$," Cement and Concrete Research, vol. 30, no. 2, pp. 247-251, 2000.

[5] M. Foster, R. Fell, and M. Spannagle, "The statistics of embankment dam failures and accidents," Canadian Geotechnical Journal, vol. 37, no. 5, pp. 1000-1024, 2000.

[6] B. Vasarhelyi, "Statistical analysis of the influence of water content on the strength of the Miocene limestone," Rock Mechanics and Rock Engineering, vol. 38, no. 1, pp. 69-76, 2005.

[7] H. Gu, M. Tao, W. Cao, J. Zhou, and X. Li, "Dynamic fracture behaviour and evolution mechanism of soft coal with different porosities and water contents," Theoretical and Applied Fracture Mechanics, vol. 103, 2019.

[8] F. L. Pellet, M. Keshavarz, and M. Boulon, "Influence of humidity conditions on shear strength of clay rock discontinuities," Engineering Geology, vol. 157, pp. 33-38, 2013.

[9] E. Verstrynge, R. Adriaens, J. Elsen, and K. Van Balen, "Multiscale analysis on the influence of moisture on the mechanical behavior of ferruginous sandstone," Construction and Building Materials, vol. 54, pp. 78-90, 2014.

[10] Z. A. Erguler and R. Ulusay, "Water-induced variations in mechanical properties of clay-bearing rocks," International Journal of Rock Mechanics and Mining Sciences, vol. 46, no. 2, pp. 355-370, 2009.

[11] S. Tang, "The effects of water on the strength of black sandstone in a brittle regime," Engineering Geology, vol. 239, pp. 167-178, 2018.

[12] G. Lin, M. Li, Y. Chen et al., "Dynamic tensile mechanical properties and fracture characteristics of water-saturated sandstone under the freezing effect," International Journal of Geomechanics, vol. 21, no. 5, 2021.

[13] Z. Chang, Q. Cai, W. Zhou, I. M. Jiskani, and R. Wang, "Effects of the loading and unloading conditions on crack propagation in high composite slope of deep open-pit mine," Advances in Civil Engineering, vol. 2019, Article ID 3168481, 11 pages, 2019.

[14] P. Baud, W. Zhu, and T. F. Wong, "Failure mode and weakening effect of water on sandstone," Journal of Geophysical Research: Solid Earth, vol. 105, no. B7, pp. 16371-16389, 2000.

[15] H. Li, R. Shen, E. Wang et al., "Effect of water on the timefrequency characteristics of electromagnetic radiation during sandstone deformation and fracturing," Engineering Geology, vol. 265, 2020.

[16] C. M. Haberfield and I. W. Johnston, "Determination of the fracture toughness of a saturated soft rock," Canadian Geotechnical Journal, vol. 27, no. 3, pp. 276-284, 1990.
[17] D. Guha Roy, T. N. Singh, J. Kodikara, and R. Das, "Effect of water saturation on the fracture and mechanical properties of sedimentary rocks," Rock Mechanics and Rock Engineering, vol. 50, no. 10, pp. 2585-2600, 2017.

[18] H. Zheng, Q. Cai, W. Zhou et al., "Creep behaviours of argillaceous sandstone: an experimental and modelling study," Applied Sciences, vol. 10, no. 21, p. 7602, 2020.

[19] S. Kahraman and T. Yeken, "Electrical resistivity measurement to predict uniaxial compressive and tensile strength of igneous rocks," Bulletin of Materials Science, vol. 33, no. 6, pp. 731$735,2010$.

[20] C. Khazaei, J. Hazzard, and R. Chalaturnyk, "Damage quantification of intact rocks using acoustic emission energies recorded during uniaxial compression test and discrete element modeling," Computers and Geotechnics, vol. 67, pp. 94102, 2015.

[21] L. R. Alejano and E. Alonso, "Considerations of the dilatancy angle in rocks and rock masses," International Journal of Rock Mechanics and Mining Sciences, vol. 42, no. 4, pp. 481-507, 2005.

[22] D. Li, E. Wang, D. Song, L. Qiu, and X. Kong, "Spatio-temporal evolution of apparent resistivity during coal-seam hydraulic flushing," Journal of Geophysics and Engineering, vol. 15, no. 3, pp. 707-717, 2018.

[23] X. Kong, E. Wang, X. He, Z. Li, D. Li, and Q. Liu, "Multifractal characteristics and acoustic emission of coal with joints under uniaxial loading," Fractals, vol. 25, 2017.

[24] Y. Filimonov, A. Lavrov, and V. Shkuratnik, "Acoustic emission in rock salt: effect of loading rate," Strain, vol. 38, no. 4, pp. 157-159, 2002.

[25] V. L. Shkuratnik, Y. L. Filimonov, and S. V. Kuchurin, "Regularities of acoustic emission in coal samples under triaxial compression," Journal of Mining Science, vol. 41, no. 1, pp. 44-52, 2005.

[26] L. N. Y. Wong and H. H. Einstein, "Using high speed video imaging in the study of cracking processes in rock," Geotechnical Testing Journal, vol. 32, no. 2, pp. 164-180, 2009.

[27] E. Wang, X. He, J. Wei, B. Nie, and D. Song, "Electromagnetic emission graded warning model and its applications against coal rock dynamic collapses," International Journal of Rock Mechanics and Mining Sciences, vol. 48, no. 4, pp. 556-564, 2011.

[28] L. Dexing, W. Enyuan, K. Xiangguo et al., "Mechanical properties and electromagnetic radiation characteristics of concrete specimens after exposed to elevated temperatures," Construction and Building Materials, vol. 188, pp. 381-390, 2018.

[29] Z. H. Li, Y. Niu, E. Y. Wang et al., "Experimental study on electric potential response characteristics of gas-bearing coal during deformation and fracturing process," Processes, vol. 7, no. 2, 2019.

[30] D. X. Li, E. Y. Wang, X. G. Kong, M. Ali, and D. M. Wang, "Mechanical behaviors and acoustic emission fractal characteristics of coal specimens with a pre-existing flaw of various inclinations under uniaxial compression," International Journal of Rock Mechanics and Mining Sciences, vol. 116, pp. 3851, 2019.

[31] H. Li, R. Shen, D. Li et al., “Acoustic emission multi-parameter analysis of dry and saturated sandstone with cracks under uniaxial compression," Energies, vol. 12, no. 10, 2019. 